\title{
PROBLEMS SURROUNDING PROBATION IN THE SOUTH AFRICAN PUBLIC SERVICE
}

\author{
Z BALOYI \\ A CRAFFORD \\ craffordgd@telkomsa.net \\ Department of Human Resource Management \\ University of Johannesburg
}

\begin{abstract}
The aim of the study was to investigate problems surrounding probation periods in the South African Public Service. A qualitative study was conducted to determine the views of both probationers and supervisors managing the probation process. Data was gathered by means of focus groups and individual interviews. Nine key areas were identified as being problematic, viz. clarity regarding the purpose of probation, lack of proper guidelines, the duration of probation, rotation during probation, lack of training, poor management of probation, performance management, anxiety and stress, power and authority. Recommendations are made concerning possible interventions.
\end{abstract}

Key words

Problems surrounding probation, SA Public Service

In some organisations, particularly those in the public sector, the final appointment of new candidates is subject to the successful completion of a probation period. Thus a trial period is required before granting permanent employment status. The probationary period refers to a discretionary period during which the suitability of a candidate for the post is determined and is generally viewed as part of the induction process (Andrews, 1988; Elliot \& Peaton, 1994; Fowler, 1996). Induction is defined by Fowler (1996) as "all the steps an employer can take to try to ensure that new recruits settle into their new jobs quickly, happily and effectively" (p. 5). During the probation period, supervisors regularly appraise the probationers' performance in order to check on their progress, and to alleviate problem areas as they occur. This provides a means for determining characteristics of a new employee that are not assessed by tests or other evaluation techniques, and can, to an extent, combat subjectivity involved in selection. Information, normally unavailable before hiring, comes to the fore that may enable supervisors and managers to gauge the quality of fit between employees and 1. the job and 2. the organisation (Masango \& Hilliard, 1999). This in turn provides an opportunity to remedy inappropriate placements thus improving the quality of the organisation's employees (Gomez-Mejia, Balkin \& Cardy 1995; Loh, 1994; Masango \& Hillard, 1999).

The probation period can also be regarded as beneficial to new employees as it fulfils an important socialisation function, through which employees are inducted into the organisation and are familiarised with the work situation. This allows for a period of adaptation in which both cognitive and perceptual gaps with regard to the new work situation can be bridged. These may arise as result of differences between duties and responsibilities of the previous job and the current position, or because the person is working for the first time (Masango \& Hilliard, 1999). In addition a probation period allows people who have no experience, the opportunity for gaining practical exposure before permanent appointment (Masango \& Hilliard, 1999). Integral to the probation period is effective performance management. New employees performance can be evaluated on a regular basis and problems resolved at an early stage before these become serious (Masango \& Hilliard, 1999). The downside of performance evaluation during the probation period is a strong negative orientation because the focus is on non-performance (Miner \& Miner, 1977)

Despite possible advantages of probation periods, several disadvantages can also be identified (Gomez-Meija, Balkin \& Cardy, 1995; Masango \& Hilliard, 1999):

- Many supervisors fail to see probation as the final step in the selection process

- Supervisors lack the necessary training (skill) to administer the probation period.

- Probation periods may be abused by supervisors who allow their personal feelings to influence them when assessing and supervising probationers.

- Orientation (induction) is sometimes done after the employee has completed the probation period.

- Probation periods are normally handled in a piecemeal fashion.

- Periods of probation can generate anxiety amongst probationers.

- In most instances, probationers do not receive normal employee benefits.

When reviewing the literature on the use of probation periods in work organisations, there appears to be little theoretical analysis of the practice and few empirical studies of the topic have been undertaken (Loh, 1994). Elliot and Peaton (1994) highlight a general lack of qualitative groundwork regarding probation periods and state that research in this area is required.

The South African Public Service has a high incidence of probation as prescribed by legislation. This practice has evolved over the years with inherent shortcomings and problems and the focus of this study is an investigation into the problems surrounding probation in a Department of the Public Service. For this reason, a more detailed discussion of probation in the South African Public Service, will follow.

\section{Probation in the South African Public Service}

Probation periods in the South African Public Service are compulsory and prescribed by legislation. Probationary appointments are regulated by the Public Service Regulations No. 44 of 2001, the Public Service Act No.103 of 1994 and Amendment Section 8 of the Labour Relations Act of 2002. The Labour Relations Act of 1995, subparagraph 8 provides that the 
probationary period must be of a reasonable duration; depending on the nature of the job and the time it takes to determine the employee's suitability for continued employment. Before the adoption of the Public Service Regulations of 1999, the Public Service Staff Code (1994) governed probationary appointments. The code prescribed that all permanent appointments be effected after twelve calendar months and while the code is no longer applicable in the public service, the practice of twelve-month probation continues. The white Paper on Human Resources Management in the Public Service (1997), an effort to modernise Human Resources practices in the public service, recommends a minimum of three and maximum of six months probation period. This, however, has not had an impact on the practice of twelve-month probation periods.

The Public Service Code (1994) also introduced a system of administering quarterly reports for the purposes of tracking the progress of new employees and was intended to lay the basis from which confirmation of permanent employment; extension or termination of probation, was conducted. This practice is currently still in use.

The latest amendment of the Labour Relations Act No.12 of 2002 stipulates, that, in so far as it may be necessary, the employer of probationers must provide reasonable evaluation, instruction, training, guidance or counselling to the employee. The employer is also obliged to inform the employee of the areas in which the required performance standards have not been met. Dismissal during the probationary period may only be contemplated after certain procedures have been complied with and should be followed by an opportunity for the new employee to state his/her case and to be assisted by a trade union representative or fellow employee.

In addition, the White paper on Human Resource Management in the Public Service (1997) indicates that clear requirements should be laid down on how newly appointed staff will be assessed during the probation period and that these criteria should be disclosed to the new employee.

In the public service, supervisors are expected to play a prominent role in the management of probation. The supervisor must ensure that the probationer is properly briefed in terms of expected performance standards and other relevant requirements for obtaining confirmation of permanent appointment. They are expected to compile and submit quarterly reports on the progress of probationers and provide them with feedback regarding the level of compliance with performance requirements. The form currently used as the basis for performance evaluation assesses probationers on the following dimensions: attendance, zeal, thoroughness and accuracy, conduct, friendliness and helpfulness, willingness to learn, sobriety, appearance and dress code, and general progress.

In addition to managing performance, supervisors are expected to conduct training aimed at developing the probationer, provide counselling where necessary and assist the probationer to meet the requirements for confirmation of permanent status. Finally, the supervisor recommends confirmation of permanent status, and extension or termination of probation.

The Human Resource Department is responsible for managing the administrative aspects of probation by means of Persal, a computerised Human Resources Information System. HR practitioners are expected to capture the personnel particulars of a probationer, the organisational unit in which he or she is placed, the dates of a probationer's appointment as well as the quarterly probation reports. HR practitioners must ensure that all new appointees are provided with a written contract of employment including terms and conditions of his/her service.
Once all four quarterly reports are captured, the HR Department issues a confirmation letter to the probationer confirming permanent employment status.

\section{RESEARCH PROBLEM}

The Department under study is the custodian of legislation intended to equip South African organisations to compete globally, by developing a competitive edge. To make this vision a reality the Department must attract and retain skilled personnel of a high quality, who will be able to deliver the desired outcomes. If the probation periods of the newly acquired personnel are not properly managed this may impact negatively on productivity, efficiency and effectiveness. It is against this background that the problems surrounding the management of probation periods warrant investigation.

\section{RESEARCH DESIGN}

In exploring the effects of probation on new employees, it was decided to use a qualitative research design. The reason being that qualitative research is helpful in determining the meanings people ascribe to routine and problematic events and allows for a deeper understanding of action in context (Babbie \& Mouton, 2001; Denzin \& Lincoln, 1994; Esterberg, 2002; Silverman, 2000).

\section{Selection of research participants}

The study was conducted at the Regional Office of the Gauteng North Provincial Directorate. Purposive sampling was used to ensure that research participants met the particular requirements needed for the study (Esterberg, 2002). For this reason, newly appointed recruits currently serving a twelvemonth probation period were selected. The supervisors were all permanent staff of the Department and have been serving in this capacity for an average of six years. None of the supervisors on probation were selected for this study. The sample group consisted of 16 probationers, and eight supervisors, in total. The composition of the focus groups was carefully chosen to ensure adequate representation in terms of race, gender and workstation. The ages of probationers varied between 21 and 32 years with the majority in entry-level positions. Supervisor ages varied between 34 and 55 years.

The members of the sample were recruited in the following manner. E-mails were sent to five Regional Offices of the Gauteng North Provincial Directorate requesting the names of officers currently on probation. Upon receiving the names of officers an invitation was sent, asking them to participate in the study. A list of supervisors was obtained from the Personnel Section and they were invited telephonically to participate in the study. The focus groups were conducted at a central venue that allowed easy access for all participants at no additional cost. The supervisors were interviewed collectively at a central venue. Thus, supervisors and probationers were interviewed in separate focus groups. In addition to focus groups, individual interviews were scheduled with lay participants and conducted at their convenience in their own offices.

\section{Data collection}

A decision was taken to use both focus groups and individual interviews to gather participants' views regarding the probation period. Focus groups, synonymous with "small-group interviews" (Esterberg, 2002, p. 108) were chosen because they allow for the views of several participants to be gathered at once, giving them the opportunity to express their views whilst explaining these to fellow group members (Babbie \& Mouton, 2001; Oates, 2000). They also allow the researcher to observe interaction and probe respondents experiences about 
this phenomena (Babbie \& Mouton, 2001; Oates, 2000). Individual interviews were used to expand on insights gained during the focus groups. These were semi-structured, so that participants were able to express their thoughts and experiences in their own words (Esterberg, 2002) while at the same time allowing the researcher to probe particular areas of interest.

Data collection began with a series of three focus groups involving the probationers. The first focus group was carried out as a pilot study to determine the feasibility of the study and to detect possible flaws in the approach (Huysamen, 1994). Each focus group began with an introduction of the researcher and the topic, and ground rules were set in place (Babbie \& Mouton, 2001). A tape recorder was used to accurately capture the responses of the participants during the interviews. Request for permission to record the interviews was obtained from participants before commencing each focus group (Oates, 2000).

The length of each focus group was between forty-five minutes and an hour. A total of sixteen probationers and eight supervisors were interviewed collectively in the focus groups. The focus groups were followed up by six individual interviews of both probationers and supervisors to explore individual perspectives on the probation period. The final combined interview was solution driven with joint participation of both probationers and supervisors deliberating on interventions for the problems that emerged during the initial interviews. All interviews and focus groups were conducted by one of the the researchers in person.

\section{Data analysis}

The data was analysed using general qualitative principles outlined by Baptiste (2001). Baptiste presents a generic framework for analyzing qualitative data. This framework is generic, in that is can be utilized regardless of the researcher's research paradigm. Baptiste identifies and elaborates on three phases in the analysis process. The first phase entails "defining the analysis" (pp. 4-8), in which the researcher selects a research paradigm within which to work. The second phased, "classifying data" (pp. 8-10) involves tagging the data and grouping it into categories. Thirdly, the researcher engages in "making connections - constructing stories and theories" (pp.10-11). During this third and final phase, the researcher develops and connects categories into "full-fledged stories or theories" (Baptiste, 2001, p. 11). Data analysis in the present study began with reading the transcripts carefully and identifying key statements. Thereafter key statements were categorised into themes and applicable codes allocated to each. Key themes were presented as the basis for the final joint focus group.

\section{Reliability and validity}

Reliability and validity are matters of concern in qualitative research and for the purpose of this study were dealt with according the guidelines prescribed by Smaling (1992). The internal reliability of the investigation was enhanced by firstly, restricting data gathering to one researcher. Secondly, the focus groups and interviews were conducted over a period of time to limit interviewer fatigue. Finally, the data was analysed in association with an academic peer to ensure consistency in outcomes and interpretation. The external reliability of the study was managed through providing thick descriptions of the way the research was conducted for example details regarding participants, events in the field and research methods.

The validity of the study was ensured by preparing a comprehensive register of the data, notes about relevant events impacting on data gathering and interpretation, the use of member checks and providing an accurate description of the research process.

\section{RESULTS}

The qualitative approach used in this study yielded a wealth of data and analysis yielded nine themes or problems relating to the probation period. Each of these is discussed below. All statements by participants are quoted verbatim and no corrections to grammar have been made.

\section{Purpose of probation period}

It emerged that both probationers and supervisors had a general understanding regarding the purpose of the probation period but lacked agreement regarding the specific purpose. Probationers viewed the period as a developmental opportunity. This is reflected in the following statement: "I would like to say that the purpose of probation is good, it enables you to know your weak points and strengths". One of the supervisors interpreted the purpose of probation as establishing loyalty and commitment to the public service, and imparting good values and practices required of dedicated public servants. This indicates a clear purpose of socialisation. Another supervisor defined the purpose of probation as a bridging programme for new staff.

\section{Absence of an official policy on probation}

It was evident that both probationers and supervisors felt strongly about the fact that no official policy exists to regulate the probation period. This is reflected in the following statement by one of the probationers: "We do not know exactly the probation policy and there is no direction as to how the process is managed". The majority of the probationers indicated that they were unsure about what they were expected to master as probationers as well as the processes associated with probation for example how their performance was managed. Some of the probationers were of the view that a document should be drafted containing objectives of the probation period to be circulated amongst them and read in their own time. The majority, however, disagreed as they felt that it would be insufficient to have a document filed in a cabinet, and that some form of communication regarding the contents of the policy should be provided.

Supervisors also indicated frustration regarding the lack of policy as this created uncertainty in managing probation. One supervisor responded, "We do not know whether we are doing a right thing in accordance to policy procedures." A significant number of both probationer and supervisory participants expressed urgency regarding the development of an official departmental policy on probation.

\section{Duration of the probation period}

The length of the probation period was an area of contention between probationers and supervisors. Twelve probationers felt that the prescribed period of twelve months is extremely long and thus unreasonable. There was also disagreement amongst probationers regarding extensions to the probation period for poor performance. Five probationers felt they should be given an extension to improve performance whilst the others felt that the period was long enough already. Supervisors on the other hand were in agreement that the twelve-month period gave the probationers sufficient time to adjust to the work place. Supervisors reacted "This twelvemonth period allows the probationer to rotate for purposes of getting multi-skilled and developing adequately to render an integrated one stop service".

\section{Rotation}

There appeared to be consensus between supervisors and probationers on the frequency with which rotation currently take places in the Department (every three months). This emerged as a sensitive issue and probationers expressed great dissatisfaction at being rotated prematurely, without having 
gained the necessary competence in a section. One probationer mentioned "a bad thing is rotation, you rotate too quickly through sections, end up knowing nothing because you do not stay long enough in one task". Probationers indicated that supervisors had very different expectations of probationers and that it was difficult to adapt as they moved from supervisor to supervisor. Strong emphasis was placed on the negative impact this had on them.

Supervisors expressed the view that the period they spent with a probationer is insufficient and this should be extended to a minimum of six months before they are re-deployed to other units. This would allow time to develop a working relationship and impart the relevant skills to probationers. Typical of the reactions that emerged during the individual supervisor interviews is the following statement "The new employee on probation only stays for a short period in your section, you do not develop a working relationship and your goal is only to see them going to another section so as to relieve you".

\section{Lack of training}

Probationers mentioned a lack of training and other developmental initiatives as a problem related to the probation period. A number of probationers reported that they had only been sent for orientation training five months into the probation period. Supervisors agreed that training was not taking place as expected and was restricted to ad-hoc training in their sections. This was due to time constraints as a result of high volumes of work. For this reason, it was felt that the responsibility for training should lie with the training and development division.

\section{Poor management of probation}

Both groups mentioned a lack of competence on the part of supervisors with regard to management in general and managing probation specifically. Probationers attributed the poor management of probation to a lack of skill amongst supervisors whilst supervisors blamed the Department for a lack of general management training. Supervisors expressed a need for training in this regard. The probationers cited a number of skills they believed were lacking in supervisors and these included communication, conflict resolution, leadership/management, training, performance management and knowledge of legislation and procedures.

Supervisors reported that they had not been properly oriented and trained on various aspects of managing probation. It became evident that supervisors do not normally adhere to probation period reporting time frames, reporting only when they are reminded and normally violating probation procedures. Two individual supervisors in the study revealed that the quality of probation reports they compile is generally of a poor standard because they feel the dimensions on which probationers are assessed are not relevant. This is captured as follows: "On that probation form there is nothing that relates to performance. We are trying to measure something that is not relevant to our work".

\section{Performance management}

It was found that probationers tended to be unrealistic with regard to expectations of their own performance. For example one probationer stated, "Probationers are scored lowly on performance assessments because they are on probation". This is viewed as unrealistic because it is normal for a new person in a job to be an average performer. Supervisors highlighted their frustration that managing probationer performance was not linked to performance management in general and expressed concern regarding the lack of integration between the two systems. One supervisor revealed that in her own performance agreement she was not contracted to manage probation and said, "it is very difficult to be measured on something that you have not been contracted to do, hence absence of accountability".

\section{Anxiety and stress}

Probationers in this study used some emotionally charged statements that indicated anxiety and fear as to whether their appointments would be made permanent. These statements should be viewed in the light of young, immature people struggling to adjust to the world of work. Statements reflecting anxiety and anger included "they demean us, we are nothing", "we are regarded as dangerous because we have honours degrees" and "they deliberately hide information so that we can fail".

\section{Power/authority}

Probationers expressed the belief that supervisory power is exercised in an authoritative way. They viewed supervisors as having the power to decide their destiny and as one probationer put it "they decide whether you are in or out". There was a strong feeling among probationers that their future was at the mercy of their supervisors.

\section{RECOMMENDATIONS}

The findings that emerged in this study have implications for the management of probation, which requires a stringent review to make its purpose more relevant. It is recommended that the current programme be modelled along the lines of inservice training with major issues pertaining to the management of people, processes and systems being reconsidered. In this regard six key areas have been identified as requiring attention. These are, firstly, drafting an official Departmental policy on probation within the Public Service; secondly, improving the performance management of probationers; thirdly, improving the training and development of probationers; fourthly, implementing feedback and support structures; fifthly, encouraging probationers to utilize existing HRM structures and finally, developing a life skills course for probationers. These six recommendations are elaborated upon below.

An official Departmental policy on the probation period must be drafted quite urgently to enable both supervisors and probationers to understand the main purpose of probation, to provide guidelines regarding matters pertaining to the management of probation and clarify their roles in terms of rights, powers and responsibilities. This must be done in line with legislative requirements and it is recommended that the guidelines of the White Paper on Human Resources Management in the Public Service be consulted in this regard as well.

Although The White Paper on Human Resources Management recommends a period of between three and six months for probation, the current duration of twelve calendar months appears to be more realistic given the nature of work the probationer is expected to master. It is also recommended that the duration of rotation periods be extended from every three to every six months. This is based on the views expressed by probationers that quarterly rotation has proven to be disempowering because they are redeployed before they are competent.

A major issue emerging from the study is the manner in which performance management is conducted. It is suggested that the performance of probationers be managed under the current performance management system of the Department and not according to practices that had their origin in the outdated Public Service Code. It is clear that the dimensions used to evaluate the performance of probationers are currently inappropriate and the 
existing quarterly report format does not add value because the behavioural dimensions used are subject to a variety of individual interpretations. The current performance management system allows for joint determination of performance goals in relation to the work done by the probationer, regular feedback regarding progress and joint assessment of performance. It also makes provision for managing the underperformance of employees, should this be required, during the probation period. In the light of the above, it is recommended that the current performance management system, with slight modifications with regard to typical performance matters common to the probation period, be adopted.

Closely related to performance management, the issue of training and development was highlighted as requiring attention by both probationers and supervisors. To address the current adhoc training received by probationers, it is recommended that a formal training schedule be introduced specifying minimum training to be undertaken by probationers. These would include aspects such as the prescribed legislation, Departmental policies and procedures, and work processes. The training schedule should be monitored as part of probation management. It is also recommended that a holistic programme aimed at supervisors be developed with regard to managing probation periods. Such a programme would cover aspects such as communication, mentorship, interviewing, knowledge of legislation, counselling, performance management and basic management skills.

Because the probation period can be a source of anxiety and uncertainty amongst probationers, the following are recommended. Firstly, it is suggested that feedback and support structures be implemented. These may take the form of joint feedback sessions where supervisors and probationers will address issues relating to progress in the spirit of open and honest communication. Secondly, the probationers should be encouraged to utilise existing HRM structures, for example the Employee Assistance Programme, a Trade Union Representative or Employment Services Practitioners (Career Counsellors). Finally, a life skill course should be developed to equip probationers to deal with the daily demands of the work place.

To address the matter of authoritative leadership amongst supervisors it is advised that a programme be developed that will equip supervisors with skills to enhance interpersonal relations and to effectively maintain sound employee relations. In addition, supervisors should be sensitised to the stress experienced by probationers, and encouraged to support the integration of probationers into the workplace. Finally, the Department may need to revise the current emphasis on hierarchy ("the rank mentality") through some form of intervention aimed at developing organisational culture.

\section{DISCUSSION}

There are two main shortcomings of the current study. Firstly, because purposive sampling was used, and a small sample was drawn only from one organization, the external validity of the findings is adversely affected. However, the goal of the research was to generalise findings to other probationers and their supervisors in the Public Service, who did not participate in the study, and this has been achieved.

Secondly, at the time that the study was conducted, one of the the researchers occupied a senior managerial position in the Department of the Public Service in which the research was conducted. It is thus possible that the participants' perception of the researcher influenced the way in which they responded to interview questions. For this reason, the external reliability of the study may have been adversely affected. However, because the research formed part of a master's study it was difficult to make use independent interviewers outside of the organisation.

\section{CONCLUSION}

The current study makes at least two significant contributions. Firstly, it exposes the problems present in the current probation system within the Public Service, and suggests ways to improve the situation. Secondly, given that little literature exists on probation, the research is a step towards building a comprehensive body of literature on the topic.

The study was conducted based on the assumption that a probationary period would remain in place. Further research should focus on whether or not probation is the most effective way to ensure best performance on the part of new employees, especially within the context of the public service. If probation is found to be the best means, the optimal structure and length of the probationary period will need to be determined, by means of further research.

\section{REFERENCES}

Andrews,Y. (1988). The personnel function (1st ed.). Pretoria: Haum Educational.

Babbie, E. \& Mouton, J. (2001). The practice of social research (SA edition). Cape Town: Oxford University Press.

Baptiste, I. (2001). Qualitative data analysis. (on line). Forum for qualitative socialr esearch. (http://www.qualitative-research. net/fqs).

Denzin, N.K. \& Lincoln, Y.S. (1994). The handbook of qualitative research. Thousand Oaks: Sage.

Elliot, R.H. \& Peaton, A.L. (1994). The probation period in the selection process: A survey of its use at the state level. Public Personnel Management, 23 (1),47-59.

Esterberg, K.G. (2002). Qualitative methods in social research. Boston, MA: McGraw-Hill.

Fowler, A. (1996). Employee induction: A good start (3rd ed.). London: Institute of Personnel and Development.

Gomez-Mejia, L.R., Balkin, D.B. \& Cardy, R.L. (1995). Managing human resources. Englewood Cliffs, N.J.: Prentice Hall.

Huysamen, G.K. (1994). Methodology for the social and behavioural sciences (1 $1^{\text {st }}$ ed.). Halfway House: Southern Publishers.

Loh, E. S. (1994). Employment Probation as a sorting out mechanism. Industrial and Labour Relations Review, 47 (3), 471-486.

Masango, R. \& Hilliard, V. (1999). Probation: A contentious South African public service practice. Journal of Public Administration, 34 (2), 94-103.

Miner, J.B. \& Miner, M.G. (1977). Personnel and industrial relations: A managerial approach. New York: Macmillan.

Oates, C. (2000). In D. Burton (Ed.) Research training for social scientists. London: Sage.

Silverman, D. (2000). Doing qualitative research: A practical handbook. Thousand Oaks: Sage.

Smaling, A. (1992). Objectivity, reliability and validity. In G.J.N. Bruisma \& M.A. Zwanenburg (Eds). Methodology for management specialist: Trends and Methods. Muiderberg: Coutinho.

South Africa. (1995). Labour Relations Act. (Act 66 of 1995). Pretoria: Government Printers.

South Africa. (2002). Labour Relations Amendment Act. Pretoria: Government Printers.

South Africa. (1994). Public Service Act. (Act 103 of 1994). Pretoria: Government Printers.

South Africa. (1999). Public Service Regulations. Pretoria: Government Printers.

South Africa. (2001). Public Service Regulations. Pretoria: Government Printers

South Africa. (1994). Public Service Staff Code. Pretoria: Office of the Public Service Commission.

South Africa. (1997). White Paper on Human Resources Management in the Public Service. Pretoria: Department of Public Service and Administration. 